\title{
Color vision assessment following cataract surgery using anomaloscope
}

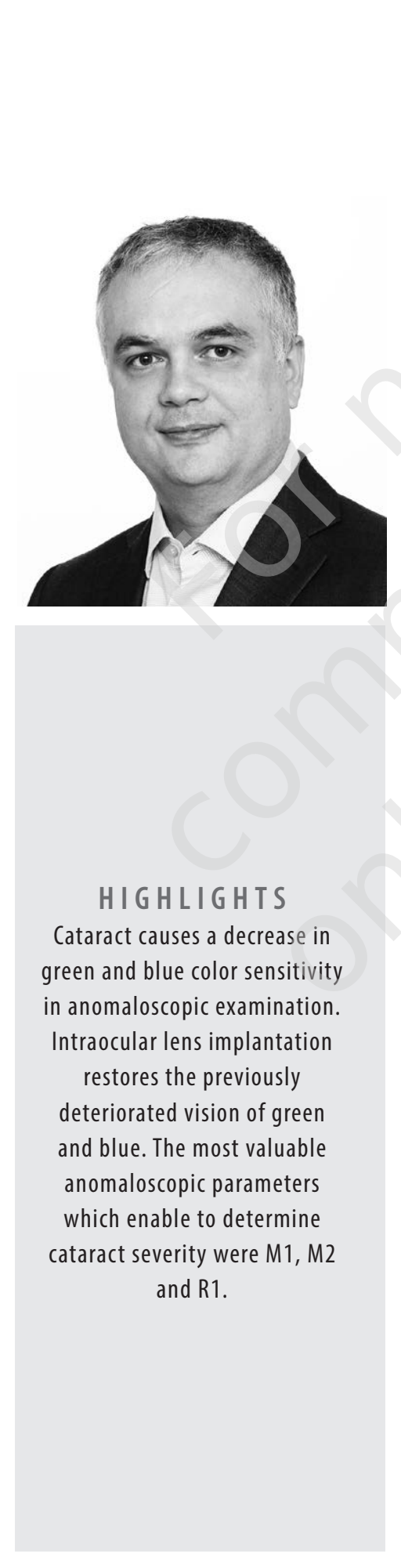

\author{
Jacek Zabel ${ }^{1,2}$, Krzysztof Piotr Michalak $^{1}$, Jan Olszewski ${ }^{2}$, \\ Maciej Koszałkowski ${ }^{3}$, Anna Przekoracka-Krawczyk ${ }^{1}$
}

'Laboratory of Vision Science and Optometry, Faculty of Physics, Adam Mickiewicz University in Poznan, Head: Prof. Ryszard Naskręcki, PhD ${ }^{2}$ Bionics and Experimental Medical Biology Karol Marcinkowski Medical University in Poznan Head: Prof. Ewa Marzec, PhD

${ }^{3}$ Laguna Medical Head: Piotr Zawadzki, MD

\section{ABSTRACT}

Aim: To evaluate the impact of cataract on color vision detection using an anomaloscope.

Methods: 12 patients aged 64-82 years with history of cataract surgery in one eye and mature cataracts in the other eye were examined for color vision using the Rayleigh and the Moreland anomaloscope tests.

Results: Different patterns of blue and green color vision deterioration have been observed in the eye with cataract as compared to the IOL eye. A decrease in M1 to approximately 1 (the minimum of the Moreland test scale) was observed in 5 out of 12 participants, whereas an increase in M2 to 99 (the maximum of the Moreland test scale) was observed in 6 out of 12 subjects. R1 found in the Rayleigh test was significantly lower in the cataract eyes as compared to the IOL eyes $(38.9 \pm 2.3$ vs. $43.4 \pm 1.6 ; \mathrm{p}<0.001)$.

Conclusions: It has been shown that cataract causes a decrease in color sensitivity, especially affecting green and blue colors. Following IOL implantation, the previously deteriorated vision of green and blue was clearly improved. The most valuable parameters of the anomaloscope test, which enable to determine cataract severity, were M1, M2 and R1.

Key words: cataract, color vision deficits, anomaloscope, Moreland test, Rayleigh test 


\section{INTRODUCTION}

Color vision is an important part of visual function. Color perception depends on light transmittance via the optical system (i.e. the cornea, the pupil and the crystalline lens), light detection in the photoreceptors, transduction of post-receptor channels and signal decoding in the visual cortex [1-4]. All aspects of human color vision are significantly affected by ageing [5-7] as color discrimination declines with age, especially along the yellow-blue axis [8-11]. The knowledge concerning the extent and type of color vision deterioration in cataract patients is rather scarce since elderly subjects with cataract are usually excluded from such studies since the disease impairs contrast sensitivity and color vision sensitivity [12-14].

Cataract is one of the major causes of visual acuity deterioration both in the elderly and in young individuals [15-22]. It is also the cause of color vision impairment, especially in the range of blue and green. A comprehensive analysis was performed by Ao et al. [23]. The authors described the results of color vision examination using Total Error Score (TES) of Farnsworth-Munsell 100-hue test (FM) in cataract patients, both prior to and following surgery, and in elderly volunteers under photopic (1000 lx) and mesopic (40 lx) conditions. Impaired perception was observed in prior to surgery subjects at $1000 \mathrm{~lx}$ illumination in the yellow to green-yellow (Y-GY), green-yellow to green (GY-G), green to blue-green (G-BG) and blue-green to blue (BG-B) color bands ( $\mathrm{p}<0.003$ ), which corresponds to the 470-580 nm range of the visible light spectrum. Under mesopic conditions, the effect was extended to all color bands except for the yellow-red to yellow (YR-Y). Postoperatively, the results did not differ significantly as compared to the control group. The researchers also measured the parameters of cataract, using LOCS III scale, such as nuclear color (NC), nuclear opalescence (NO), cortical opalescence $(\mathrm{C})$ and posterior subscapular opalescence (PS) and correlated them with the FM test results. They found that subsequent LOCS III parameters were correlated with different color ranges in the FM test. Under more sensitive mesopic conditions, NC was correlated mainly with the G-BG, BG-B and B-PB ranges and NO was correlated mainly with G-BG, P-RP and RP-R (R-red, P-purple) ranges in the FM test. This suggests that cataract patients may suffer from impaired vision in various hue ranges.

Another research, focused on the impact of cataract on color vision, was presented by Mehta et al. [24]. The researchers used the High-Definition Cone Contrast Test (CCT), prior to and following surgery, to measure cataract-related changes in color vision. The CCT score difference between prior to and following surgery examinations was significant for the blue (33.0 CCT units) and green cones (24.9) but not significant for the red cones (22.0). However, the study showed that in non-cataract subjects the test score decreased with age, mostly for the S-cones (CCT score vs. age, slope $=-1.25$ ), slightly less for the $\mathrm{M}$-cones (slope = -1.13 ) and only slightly for the L-cones (slope $=-0.49$ ).

In the studies mentioned above, different color vision tests were used to find the most sensitive and readily available method useful for early diagnosis of cataract and its monitoring. In general, the "gold standard" for measuring color vision deficits is an anomaloscopic examination [25]. The HMC Anomaloskop MR47700 includes two tests i.e. the Rayleigh test, which has been commonly adopted and measures the sensitivity to red and green colors, and the Moreland test, which measures the relation between the blue and green color sensitivity [26, 27]. The idea of the Rayleigh test is based on finding the proportion of red $(666 \mathrm{~nm})$ and green light $(549 \mathrm{~nm})$ intensity that results in a hue impression identical to the yellow reference diode (589 nm). Similarly, in the Moreland test, the light emitted by the blue $(430 \mathrm{~nm})$ and green $(490 \mathrm{~nm})$ diodes is mixed and the resulting hue is compared against the reference cyan diode $(480 \mathrm{~nm})$. As shown in our previous studies [26, 27], the device is sensitive mainly to deficits in the red-green axis (the Rayleigh test, Oculus anomaloscope). Color vision changes in the blue-green axis are much harder to detect using the Moreland test provided by the Oculus anomaloscope [27]. As the crystalline lens begins to lose translucency with age, absorption of short-wave visible light increases, leading to tritanopia-like deficits $[28,29]$. Therefore, a question arises whether the Moreland test is actually useful for detection of color vision deficits in cataract eyes.

The aim of the current study was to perform an initial analysis concerning the potential use of anomaloscope for determination of color vision deficiencies in cataract patients.

\section{MATERIALS AND METHODS}

\section{Subjects}

The inclusion criteria were as follows: age over 50 years; diagnosed binocular age-related mature cataract (best corrected visual acuity (BCVA) no more than $0.2 \log M A R)$; 2-4 weeks following cataract surgery in the eye with inferior visual acuity (i.e. more advanced cataract); no ocular pathology confirmed during an ophthalmological examination using slit lamp with Volk lens (the examiner was an experienced ophthalmologist and one of the authors - Maciej Koszałkowski); no history of ocular pathology, ocular trauma or strabismus; no history of color vision deficits.

Twelve subjects participated in the study ( 9 female and 3 male) and 24 eyes were examined: 12 following cataract surgery ( $\mathrm{SE}$ - surgery eye) and 12 prior to the surgery (CE - cataract eye). The subjects were aged between 64 and 82 years. The mean best corrected visual acuity (BCVA) in the CE was logMAR $0.31 \pm 0.14$, while the mean BCVA 
in the SE was $\operatorname{logMAR} 0.06 \pm 0.06$ (acuities were taken two to four weeks following the surgery). Detailed information about BCVA and cataract types is included in table 1 [30]. The IOL Auroflex, a hydrophilic aspheric lens made of P-HEMA (poly hydroxyethyl methacrylate; Aurolab/India), was implanted in all the eyes. was performed using the Snellen chart at 5 meters. The refractive error in the SE was compensated by the IOL. Spectacle correction was used as necessary in front of the CE. Color vision test was administered in a dim room using the HMC Anomaloskop MR47700 (Oculus). The test protocol was in accordance with the device user's manual [31] and

\section{TABLE $(1$}

Best Corrected Visual Acuity (BCVA) in surgery eyes (SE) and cataract eyes (CE). Cataract classification according to LOCS III (Lens Opacities Classification System). Types of cataract: $\mathbf{N}$ - nuclear, $\mathrm{C}$ - cortical, P - posterior.

\begin{tabular}{|c|c|c|c|c|}
\hline Subject & SE BCVA logMAR & CE BCVA logMAR & CE LOCS III & CE type of cataract \\
\hline 01 & 0.10 & 0.30 & $\mathrm{NC} 4, \mathrm{C} 2$ & $\mathrm{~N}$ \\
\hline 02 & 0.10 & 0.30 & $\mathrm{NC} 3, \mathrm{C} 1$ & $\mathrm{~N}$ \\
\hline 03 & 0.10 & 0.49 & $\mathrm{NC} 4, \mathrm{C} 2$ & $\mathrm{~N}-\mathrm{C}$ \\
\hline 04 & 0.05 & 0.49 & $\mathrm{NC} 4, \mathrm{C} 2$ & $\mathrm{~N}-\mathrm{C}$ \\
\hline 05 & 0.05 & 0.30 & $\mathrm{NC} 3, \mathrm{C} 2$ & $\mathrm{~N}-\mathrm{C}$ \\
\hline 06 & 0 & 0.10 & $\mathrm{NC2}, \mathrm{C} 3$ & C \\
\hline 07 & 0 & 0.49 & $\mathrm{NC} 4, \mathrm{C} 2$ & $\mathrm{~N}-\mathrm{C}$ \\
\hline 08 & 0 & 78 & $\mathrm{NC} 3, \mathrm{C} 2$ & $\mathrm{~N}-\mathrm{C}$ \\
\hline 09 & 0 & 0.20 & $\mathrm{NC} 3, \mathrm{C} 1$ & $\mathrm{~N}$ \\
\hline 10 & 0.05 & 0.10 & $\mathrm{NC2}, \mathrm{P} 1$ & $P$ \\
\hline 11 & 0.20 & 0.30 & $\mathrm{NC} 3, \mathrm{C} 3$ & $\mathrm{~N}-\mathrm{C}$ \\
\hline 12 & 0.05 & 0.30 & $\mathrm{NC3}, \mathrm{P} 1$ & N-P \\
\hline
\end{tabular}

The study has been approved by the local Ethics Committee at the Poznan University of Medical Sciences and the study protocol was designed in accordance with the Declaration of Helsinki (no. 1111/18). A prior informed consent has been obtained in writing from each participant.

\section{Procedure and analysis}

The study was performed in the ER-MED Medical Center (located in Pila, Poland). All participants underwent cataract surgery with intraocular lens (IOL) implantation (Auroflex, US) in one eye only. The implanted IOL was a hydrophilic aspheric lens made of poly hydroxyethyl methacrylate (P-HEMA) with 25\% water content. Color vision and visual acuity assessments were performed between 2 and 4 weeks following the cataract surgery. As presented in [26], two eyes of young healthy individuals did not differ significantly in terms of the results of anomaloscopic color vision test. Thus, the comparison was made between the cataract and surgery eyes for each subject. Due to the age of the participants and pandemic-related limitations of recruitment, the research was limited and both eyes were tested during the same study visit. The first measurement was taken in the SE in order to allow the subjects to get familiar with the research task using the eye with a better BCVA. Subsequently, the CE was examined. The VA test the same as described in our previous papers [26, 27]. Prior to the test, the subjects adapted to the light conditions for 10 minutes. During the test, bright circular field (size of 2 degrees) divided into halves was presented on the anomaloscope's screen. The upper part of the circle served as a reference field and the lower part was the actual test field. In the manual mode, a researcher set the variable values (i.e. color proportions) of the reference field and the observer (i.e. the subject) had to adjust the brightness of the test field so as to achieve an equal color in both halves. In case a subject was unable to match the colors, he was asked to report it to the researcher. In the Rayleigh test, the proportion of red and green light was adjustable. In the Moreland test, blue and green light was used. Details of the procedure are described in [26].

The aim of the measurement was to define the limits of the range of color proportions in the reference field within which the subjects were able to match the colors in both halves of the test projection.

The following set of four parameters was analyzed from the data obtained in both the Rayleigh and the Moreland tests: $R_{1}$ - the lower limit of the matching range for the Rayleigh test, $R_{2}$ - the upper limit of the matching range for the Rayleigh test, $R_{C}=\left(R_{1}+R_{2}\right) / 2$ - central matching for the Rayleigh test, $R_{w}=R_{2}-R_{1}$ - the width of the matching range 
for the Rayleigh test, $M_{1}$ - the lower limit of the matching range for the Moreland test, $\mathrm{M}_{2}$ - the upper limit of the matching range for the Moreland test, $M_{C}=\left(M_{1}+M_{2}\right) / 2$ - central matching for the Moreland test, $M_{w}=M_{2}-M_{1}$ - the width of the matching range for the Moreland test. As discussed in our previous studies [26, 27], the decrease in $\mathrm{R}_{1}$ corresponds mainly to the deterioration in green color visibility, while the increase in $R_{2}$ mainly corresponds to the deterioration in red color visibility. Similarly, the decrease in $M_{1}$ corresponds mainly to poorer blue color visibility and the increase in $\mathrm{M}_{2}$ to inferior green visibility. Increased $R_{w} /$ $\mathrm{M}_{\mathrm{W}}$ reflects a lower ability to distinguish hues and tones in the red-yellow-green and the blue-cyan-green axes, respectively.

In case of four parameters, the comparison was made using the Student's t-test due to the rejection of the thesis concerning the abnormal distribution of both compared variables in the Shapiro-Wilk test. For the four parameters $\left(R_{2}, R_{W}, M_{1}\right.$ and $\left.M_{2}\right)$, the comparison was based on the Wilcoxon test due to the abnormal distribution of one of the variables. An additional F-test analysis of the variance equality was performed to show significant changes in the ranges of the study parameters measured following cataract surgery. The test is able to detect the parameters which increase or decrease, depending on the kind of the cataract, even though the mean value may not change significantly, the spread in the population will decrease.

Statistica 13.1 software (StatSoft) was used for statistical analysis. Statistical significance was achieved when the $\mathrm{p}$-value was less than or equal to 0.05 .

\section{RESULTS}

Table 2 shows the results of individually measured Rayleigh and Moreland test parameters for two eyes, one before cataract surgery and the other one following the surgery. It is noticeable that the parameters $\mathrm{R}_{1}$ and $\mathrm{R}_{\mathrm{C}}$ showed higher values in the $S E$ than in the $C E\left(R_{1}: 43.4\right.$ vs. 38.9 ; $p<$ 0.001 for the $S E$ and the CE, respectively; $R_{C}: 45.9$ vs. 42.6 ; $\mathrm{p}<0.001$, for the SE and the CE, respectively). Conversely, $\mathrm{R}_{\mathrm{w}}$ showed lower values in the SE (5.0 vs. 7.5; $\left.\mathrm{p}<0.05\right)$. There were no significant differences for $R_{W}$ and the remaining Moreland test parameters ( $p>0.05)$. In the variance equality $F$ test, $M_{2}$ showed a significantly higher variance in the CE than in the $\mathrm{SE}\left(\operatorname{std}\left[\mathrm{M}_{2}\right]: 15.3\right.$ vs. $6.2 ; \mathrm{p}<$ 0.01 ). There was no significant difference in the variance prior to and after the surgery for the remaining analyzed parameters.

A visual inspection of the distribution of the $M_{1}$ parameter in cataract patients showed that 5 out of 12 patients obtained only minimal or nearly minimal values (4 subjects with $M_{1}=1$ and 1 subject with $M_{1}=5$ ) and the remaining 7 subjects exhibited $M_{1}$ between 20 and 43. This parameter represents mainly the deterioration in the blue color sensitivity. Thus, due to the specific distribution of this parameter, an additional analysis was performed for the groups with $M_{1} \leq 5(\mathrm{~N}=5)$ and $M_{1} \geq 20(N=7)$. All five subjects from the $M_{1} \leq 5$ group showed a higher $M_{1}$ value in the SE ranging between 23 and 43 . Table 3 presents the results for both eyes in the $M_{1} \leq 5$ and $M_{1} \geq 20$ groups.

It may be noticed that the subjects from the $M_{1} \leq 5$ group (more severe blue vision deficits) differed significantly between the SE and the CE in terms of the following parameters: $\mathrm{R}_{1}, \mathrm{R}_{2}, \mathrm{R}_{\mathrm{C}}, \mathrm{M}_{1}, \mathrm{M}_{\mathrm{W}}$ and $\mathrm{M}_{\mathrm{C}}\left(\mathrm{R}_{1}: 43.7\right.$ vs. $38.4 ; \mathrm{p}<0.001$; $\mathrm{R}_{2}: 47.7$ vs. $44.5, \mathrm{p}<0.05 ; \mathrm{R}_{\mathrm{C}}: 46.2$ vs. $41.5 ; \mathrm{p}<0.01 ; \mathrm{M}_{1}: 31.0$ vs. $1.8 ; \mathrm{p}<0.01 ; \mathrm{M}_{\mathrm{W}}: 55.9$ vs. $87.4 ; \mathrm{p}<0.01 ; \mathrm{M}_{\mathrm{C}}: 58.9$ vs. 45.5 ; $\mathrm{p}<0.05)$. There were no significant differences in terms of $R_{W}$ and $M_{2}$. In the group with higher $M_{1}$ values $\left(M_{1} \geq 20\right)$, a significant difference was observed only in the $R_{1}$ and $R_{W}$ Rayleigh test parameters $\left(\mathrm{R}_{1}: 43.1\right.$ vs. $39.3 ; \mathrm{p}<0.01 ; \mathrm{R}_{\mathrm{w}}: 5.1$

\section{TABLE $(2$}

Parameters of the Rayleigh and Moreland tests for eyes prior to and following cataract surgery. CE - cataract eye, SE - surgery eye.

$R_{1} / R_{2}$ - the lower and the upper limit of the Rayleigh test match, $R_{w}=R_{2}-R_{1}-$ the width of the Rayleigh test match, $R C=\left(R_{1}+R_{2}\right) / 2-$ central matching of the Rayleigh test. $M_{1}, M_{2}, M_{W} M_{c}$ - analogue parameters of the Moreland test.

\begin{tabular}{|c|c|c|c|c|}
\hline Parameter & $\begin{array}{c}\text { Cataract Eye } \\
\text { (CE) } \\
\mathrm{N}=12\end{array}$ & $\begin{array}{c}\text { Surgery Eye } \\
\text { (SE) } \\
\mathrm{N}=12\end{array}$ & $\begin{array}{c}p \\
\text { t-Student (t) or Wilcoxon (W) } \\
\text { (CE vs. SE) }\end{array}$ & $\begin{array}{l}p \\
\begin{array}{c}p \text { test for variance equality } \\
\text { (CE vs. SE) }\end{array}\end{array}$ \\
\hline $\mathrm{R}_{1}$ & $38.9 \pm 2.3$ & $43.4 \pm 1.6$ & $0.001^{* * *}(\mathrm{t})$ & 0.292 \\
\hline $\mathrm{R}_{2}$ & $46.4 \pm 3.3$ & $48.4 \pm 2.6$ & $0.092^{+}(\mathrm{W})$ & 0.467 \\
\hline $\mathrm{R}_{\mathrm{w}}$ & $7.5 \pm 3.5$ & $5.0 \pm 2.1$ & $0.028^{*}(\mathrm{~W})$ & 0.113 \\
\hline $\mathrm{R}_{\mathrm{c}}$ & $42.6 \pm 2.2$ & $45.9 \pm 1.9$ & $0.001^{* * *}(\mathrm{t})$ & 0.635 \\
\hline$M_{1}$ & $18.8 \pm 16.1$ & $29.8 \pm 13.7$ & $0.108(W)$ & 0.607 \\
\hline $\mathrm{M}_{2}$ & $87.8 \pm 15.3$ & $88.8 \pm 6.2$ & $0.964(W)$ & $0.005^{* *}$ \\
\hline$M_{w}$ & $69.0 \pm 22.4$ & $59.1 \pm 12.9$ & $0.139(\mathrm{t})$ & $0.080^{+}$ \\
\hline$M_{C}$ & $53.3 \pm 11.0$ & $59.3 \pm 8.4$ & $0.182(t)$ & 0.395 \\
\hline
\end{tabular}

${ }_{* * * * *} \mathrm{p} \leq 0.001 ;{ }^{* * *} \mathrm{p} \leq 0.01 ;{ }^{*} \mathrm{p} \leq 0.05 ;{ }^{+} \mathrm{p} \leq 0.1$. 
vs. 8.4; $\mathrm{p}<0.05)$. No significant difference was observed for the remaining parameters.

A comparison of CEs between the $M_{1} \leq 5$ and $M_{1} \geq 20$ groups showed statistical significance for $\mathrm{M}_{W}$ and $\mathrm{M}_{\mathrm{C}}\left(\mathrm{M}_{\mathrm{W}}\right.$ : 87.4 vs. 55.9; $\mathrm{p}<0.01 ; \mathrm{M}_{\mathrm{C}}$ : 45.5 vs. $\left.58.9 ; \mathrm{p}<0.05\right)$.

However, a visual inspection of the distribution of the $M_{2}$ parameter in cataract patients showed that 6 out of 12 participants exhibited the maximum value $M_{2}=99$ and for the remaining six patients $M_{2}$ ranged between 54 and 95 . This parameter represents mainly the deterioration in sensitivity to the green color. Due to such distribution of the parameter, an additional analysis was performed for the $M_{2}=99$ $(N=6)$ and $M_{2} \leq 95(N=6)$ groups. In the $M_{2}=99$ group, three subjects belonged to $M_{1} \leq 5$ and three other to the $M_{1}$ $\geq 20$ group. All 6 subjects from the $M_{2}=99$ group showed a decrease in $M_{2}$ in the surgery eye and its values ranged between 75 and 95 . Table 4 presents the results for the $M_{2}$ $\leq 95$ and $M_{2}=99$ groups.

In the $\mathrm{M}_{2}=99$ group (more severe green vision deficits) the $\mathrm{SE}$ showed higher $\mathrm{R}_{1}$ and $\mathrm{R}_{\mathrm{C}}$ values and lower levels of the $\mathrm{M}_{2}$ parameter as compared to the $C E\left(\mathrm{R}_{1}: 43.2\right.$ vs. 38.3; $\mathrm{p}<0.001 ; \mathrm{R}_{\mathrm{C}}: 45.8$ vs. $42.4 ; \mathrm{p}<0.05 ; \mathrm{M}_{2}: 88.3$ vs. $99.0 ; \mathrm{p}<$ $0.05)$. In the group with lower $M_{2}$ values $\left(M_{2} \leq 95\right)$, a significant difference was observed for the $R_{1}, R_{C}, M_{2}$ and $M_{C}$ parameters (SE vs. CE: $\mathrm{R}_{1}$ : 43.6 vs. 39.5; $\mathrm{p}<0.05$; $\mathrm{R}_{\mathrm{C}}$ : 45.9 vs. 42.9; $\mathrm{p}<0.05 ; \mathrm{M}_{2}: 89.3$ vs. $76.7 ; \mathrm{p}<0.05 ; \mathrm{M}_{\mathrm{C}}: 62.3$ vs. 48.8; $\mathrm{p}<0.05)$. A significant difference between $M_{2}=99$ and $M_{2}$ $\leq 95$ groups was also noted in the $\mathrm{M}_{W}$ parameter in the cataract eyes $\left(\mathrm{M}_{\mathrm{w}}: 82.3\right.$ vs. $\left.55.7 ; \mathrm{p}<0.05\right)$.

\section{TABLE ( 3}

Rayleigh and Moreland test parameters in the groups characterized by low $M 1$ value $\left(M_{1} \leq 5, N=5\right.$, more severe deterioration in blue visibility) and normal $M_{1}$ values $\left(M_{1} \geq 20, N=7\right)$. (E $E^{5}$ - cataract eye, $M 1 \leq 5$ group, $S E^{5}$ - surgery eye, $M_{1} \leq 5$ group, CE 20 - cataract eye, $M_{1} \geq 20$ group, SE20 - surgery eye, $M_{1} \geq 20$ group.

\begin{tabular}{|c|c|c|c|c|c|c|c|}
\hline & $\begin{array}{c}\text { Cataract eye } \\
M_{1} \leq 5 \\
\left(\mathrm{CE}^{5}\right)\end{array}$ & $\begin{array}{c}\text { Surgery eye } \\
M_{1} \leq 5 \\
\left(S^{5}\right)\end{array}$ & $\begin{array}{c}\text { Cataract eye } \\
\mathbf{M}_{1} \geq 20 \\
\left(\mathrm{CE}^{20}\right)\end{array}$ & $\begin{array}{c}\text { Surgery eye } \\
\mathrm{M}_{1} \geq 20 \\
\left(\mathrm{SE}^{20}\right)\end{array}$ & $\begin{array}{c}\text { t-test } \\
\text { CE }^{5} \text { vs. SE }\end{array}$ & $\begin{array}{c}\text { t-test } \\
\mathrm{CE}^{20} \text { vs. SE }{ }^{20}\end{array}$ & $\begin{array}{c}\text { t-test } \\
\text { CE }^{5} \text { vs. CEE }\end{array}$ \\
\hline $\mathrm{R}_{1}$ & $38.4 \pm 0.9$ & $43.7 \pm 0.9$ & $39.3 \pm 2.9$ & $43.1 \pm 2.1$ & $<0.001^{* * * *}$ & $0.008^{* *}$ & 0.532 \\
\hline $\mathrm{R}_{2}$ & $44.5 \pm 3.6$ & $48.6 \pm 3.0$ & $47.7 \pm 2.5$ & $48.2 \pm 2.5$ & $0.049^{*}$ & 0.696 & $0.094^{+}$ \\
\hline $\mathrm{R}_{\mathrm{w}}$ & $6.1 \pm 3.7$ & $4.9 \pm 2.5$ & $8.4 \pm 3.3$ & $5.1 \pm 2.1$ & 0.411 & $0.013^{*}$ & 0.279 \\
\hline $\mathrm{R}_{c}$ & $41.5 \pm 1.8$ & $46.2 \pm 1.9$ & $43.5 \pm 2.2$ & $45.7 \pm 2.0$ & $0.005^{* *}$ & $0.072+$ & 0.116 \\
\hline$M_{1}$ & $1.8 \pm 1.8$ & $31.8 \pm 8.8$ & $31.0 \pm 7.5$ & $28.3 \pm 16.9$ & $0.002^{* * *}$ & 0.634 & - \\
\hline $\mathrm{M}_{2}$ & $89.2 \pm 19.8$ & $89.0 \pm 5.7$ & $86.9 \pm 12.9$ & $88.7 \pm 6.9$ & 0.978 & 0.770 & 0.808 \\
\hline$M_{w}$ & $87.4 \pm 19.3$ & $57.1 \pm 12.2$ & $55.9 \pm 13.7$ & $60.4 \pm 14.2$ & $0.008^{* *}$ & 0.337 & $0.008^{* *}$ \\
\hline$M_{c}$ & $45.5 \pm 10.2$ & $60.4 \pm 4.2$ & $58.9 \pm 8.1$ & $58.5 \pm 10.8$ & $0.034^{*}$ & 0.938 & $0.028^{*}$ \\
\hline
\end{tabular}

\section{TABLE $(4$}

Rayleigh and Moreland test parameters in the groups showing a maximum $M_{2}$ value $\left(M^{2}=99, N=6\right.$, more severe deterioration in green visibility) and lower $M_{2}$ values $\left(M_{2} \leq 95, N=6\right)$. Groups: (E99: Cataract Eye, $M_{2}=99$ group; SE 99 : Surgery Eye, $M_{2}=99$ group; CE95: Cataract Eye, $M_{2} \leq 95$ group; $S E^{95}$ : Surgery Eye, $M_{2} \leq 95$ group.

\begin{tabular}{|c|c|c|c|c|c|c|c|}
\hline & $\begin{array}{c}\text { Cataract eye } \\
\mathrm{M}_{2}=99 \\
\left(\mathrm{CE}^{99}\right)\end{array}$ & $\begin{array}{c}\text { Surgery eye } \\
M_{2}=99 \\
\left(\mathrm{SE}^{99}\right)\end{array}$ & $\begin{array}{c}\text { Cataract eye } \\
\mathrm{M}_{2} \leq 95 \\
\left(\mathrm{CE}^{95}\right)\end{array}$ & $\begin{array}{c}\text { Surgery eye } \\
M_{2} \leq 95 \\
\left(\mathrm{SE}^{95}\right)\end{array}$ & $\begin{array}{c}\text { t-test } \\
\text { CE }^{99} \text { vs. SE } \text { SE }^{99}\end{array}$ & $\begin{array}{c}\text { t-test } \\
\text { CE }^{95} \text { vs. SE }\end{array}$ & $\begin{array}{c}\text { t-test } \\
\text { CE }^{99} \text { vs. CE }{ }^{95}\end{array}$ \\
\hline $\mathrm{R}_{1}$ & $38.3 \pm 0.8$ & $43.2 \pm 1.3$ & $39.5 \pm 3.1$ & $43.6 \pm 2.0$ & $0.001^{* * *}$ & $0.014^{*}$ & 0.400 \\
\hline $\mathrm{R}_{2}$ & $46.5 \pm 3.8$ & $48.5 \pm 2.4$ & $46.3 \pm 3.0$ & $48.3 \pm 3.0$ & 0.273 & 0.228 & 0.902 \\
\hline $\mathrm{R}_{\mathrm{w}}$ & $8.2 \pm 3.8$ & $5.3 \pm 1.9$ & $6.7 \pm 3.4$ & $4.7 \pm 2.5$ & $0.058^{+}$ & 0.150 & 0.513 \\
\hline $\mathrm{R}_{c}$ & $42.4 \pm 2.0$ & $45.8 \pm 1.7$ & $42.9 \pm 2.6$ & $45.9 \pm 2.2$ & $0.026^{*}$ & $0.044^{*}$ & 0.737 \\
\hline$M_{1}$ & $16.7 \pm 17.4$ & $24.2 \pm 16.1$ & $21.0 \pm 15.9$ & $35.3 \pm 8.8$ & 0.515 & $0.064^{+}$ & 0.662 \\
\hline $\mathrm{M}_{2}$ & $99 \pm 0$ & $88.3 \pm 6.9$ & $76.7 \pm 14.7$ & $89.3 \pm 5.9$ & $0.013^{*}$ & $0.038^{*}$ & - \\
\hline$M_{w}$ & $82.3 \pm 17.4$ & $64.2 \pm 12.3$ & $55.7 \pm 19.4$ & $54.0 \pm 12.3$ & 0.133 & 0.804 & $0.031^{*}$ \\
\hline$M_{c}$ & $57.8 \pm 8.7$ & $56.3 \pm 10.8$ & $48.8 \pm 11.9$ & $62.3 \pm 4.2$ & 0.802 & $0.025^{*}$ & 0.166 \\
\hline
\end{tabular}

***: $\mathrm{p} \leq 0.001 ; * \mathrm{p} \leq 0.01 ; * \mathrm{p} \leq 0.05 ;{ }^{+} \mathrm{p} \leq 0.1$ 


\section{DISCUSSION}

The aim of the study was to analyze the influence of cataract on anomaloscopic parameters of color vision. To date, the influence of cataract on color vision was analyzed using the Farnsworth-Munsell 100-Hue test [23] and the Cone Contrast Test [24]. Anomaloscopic examination was used only to determine potential differences in color vision following the implantation of different IOLs in the same subjects or to compare color vision in IOL eyes with a control group [32-34]. However, it has not been used before to determine the changes in color vision caused by lenses affected by cataract. Thus, the answer to the question concerning the use of anomaloscope to monitor cataract-related changes remains unclear.

The analysis of the results obtained in the present study leads to the conclusion that the impact of cataract is evident primarily in the red-green axis of the Rayleigh test. A statistically significant improvement in this test following surgery was found for the $R_{1}, R_{W}$ and $R_{C}$ parameters. The above results suggest an improvement in vision in the green area as compared to red (increase in $R_{1}$ as a result of surgery). The $R_{2}$ parameter showed a slight increase but it did not reach the threshold of statistical significance. It might be the result of a subtle deterioration in red vision due to the spectral properties of the implanted lens or an improved transmittance of green light in the IOL, which also might affect the $\mathrm{R}_{2}$ parameter to a lesser extent [35]. The $R_{C}$ and $R_{w}$ parameters were calculated based on the $R_{1}$ and $R_{2}$ values and changed mainly due to the increase in $R_{1}$ and to a lesser extent due to the $R_{2}$ increase. A significant narrowing of $R_{W}$ indicates a better hue discrimination in the lemon-yellow-orange range following surgery.

As mentioned earlier, the $M_{1}$ parameter showed a two peak distribution, with five subjects achieving low values of $M_{1}$ equal to 1 or 5 . The remaining seven subjects showed normal values in the range between 20 and 43. The normal range of this parameter, as estimated by the authors [26], was $28.5 \pm 21.2$ with a median of 27.25 and min-max range of 1-77. It should be pointed out that in [26] 36 out of 178 (20.2\%) healthy eyes of young volunteers showed $M_{1} \leq 5$. In the present study, 5 out of 12 CEs (41.6\%) showed $M_{1}$ $\leq 5$. However, all the subjects showed a significantly higher value of this parameter in the postoperative eye, ranging between 23 and 43. This observation allowed research team to perform an additional analysis for the $M_{1} \leq 5$ group $(\mathrm{N}=5)$ and for the $M_{1} \geq 20$ group $(N=7)$. The results for the above mentioned five subjects ( $C E^{5}$ and $\mathrm{SE}^{5}$ subgroups) and for the remaining seven subjects ( $\mathrm{CE}^{20}$ and $\mathrm{SE}^{20}$ subgroups) are presented in table 3 .

Nevertheless, six subjects reached the maximum values $M_{2}$ = 99 in the Moreland test. The reference range for this parameter, as estimated by the authors [26], was $84.6 \pm 5.3$ with a median of 85.5 and a min-max range of 61-92.5.
All the subjects showed lower $\mathrm{M}_{2}$ values in SEs ranging from 75 to 95 . It is worth mentioning that none of 178 eyes analyzed in the paper [26] reached the value $M_{2}=99$.

As presented in table 2, the measured parameters of the Moreland test did not reach the statistical significance level between cataract and surgery eyes. However, the differences were significant in the analysis of subgroups $M_{1} \leq 5$, $M_{1} \geq 20, M_{2} \leq 95$ and $M_{2}=99 . M_{1}$ was significantly higher following surgery in the $M_{1} \leq 5$ subgroup, which indicates a more pronounced increase in blue color visibility in the group with higher blue vision deterioration.

Another observation which should be mentioned here is the $\mathrm{M}_{2}$ parameter, which is mainly related to green vision quality. The parameter did not differ between cataract and surgery eyes, however, the variance of this parameter decreased significantly in the eye which underwent surgery. Visual inspection of the obtained data led the authors to the observation that the parameter increased in five cases following surgery and decreased in seven cases. It was significantly lower following surgery in the $M_{2}=99$ group but significantly higher in the $\mathrm{M}_{2} \leq 95$ group. Assuming the increase in $R_{1}$ in all groups is mainly related to the increase in green visibility following surgery, the presented results for $\mathrm{M}_{2}$ indicate that certain cataract patients are characterized by a higher deterioration in blue and others in green color vision. Certain individuals might also show similar deterioration both in blue and green. This observation is in general consistent with the results of Ao et al. [23] which showed different patterns in color vision deterioration depending on the type of cataract.

The other parameter that differed significantly between cataract and surgery eyes in different groups is $M_{w}$. It mainly indicates the ability to distinguish between different hues and tones in the blue-cyan-green range. Significant differences were observed between the $\mathrm{CE}^{5}$ vs. $\mathrm{SE}^{5}, \mathrm{CE}^{5}$ vs. $\mathrm{CE}^{20}$ and $\mathrm{CE}^{99}$ and $\mathrm{CE}^{95}$ groups. It may be concluded that, in case of patients with more severe color vision deteriorations ( $\mathrm{CE}^{5}$ and $\mathrm{CE}^{99}$ groups), the deterioration in hue and tones visibility is also exacerbated. This effect is most evident in the $\mathrm{CE}^{5}$ group with blue vision deterioration. The standard deviation for this parameter decreased from 22.4 to 12.9 following surgery, which was close to the level of significance and also pointed to inter-subject variability of cataract-related color vision deterioration.

The $M_{1} \leq 5$ group represents subjects characterized by inferior ability to see blue color as compared to the remaining ones. A comparison of the examined parameters shows that, in the case of $M_{1} \leq 5$ group, cataract surgery significantly improved 6 of the measured parameters, i.e. $R_{1}, R_{2}, R_{C}, M_{1}, M_{C}$ and $M_{W}$. Their statistical significance was similar or higher despite the lower number of subjects $(\mathrm{N}=5)$ than in the main group $(\mathrm{N}=12)$. The $\mathrm{M}_{1}$ difference between the cataract eye $\left(\mathrm{M}_{1}{ }^{\mathrm{CE}}=1.8\right)$ and the surgery eye 
$\left(\mathrm{M}_{1}^{\mathrm{SE}}=31.8\right)$ reached the level of statistical significance. The postoperative increase in $M_{1}$ was accompanied by a narrowing of $M_{w}$ and an increase in $M_{C}$. These observations lead to the conclusion that the visibility of blue color was improved as compared to green. Patients in this group also experienced an increase in $\mathrm{R}_{1}$, which denotes an improvement in green vision. It may be concluded preliminarily that this group represents individuals in whom the dominant vision disorder in the cataract eye is the weakening of blue vision. It is also accompanied by the weakening of green vision but to a lesser extent.

As opposed to the $M_{1} \leq 5$ group, no improvement in $M_{1}$ following cataract surgery was observed in the $M_{1} \geq 20$ group. The remaining parameters of the Moreland test also did not improve in this group as a result of cataract surgery. However, similarly to the $M_{1} \leq 5$ group, an improvement of the green vision in the Rayleigh test was observed as an increase in $R_{1}$ value from 39.3 to 43.1 . The above results lead to a cautious conclusion that the perception of blue and green in this group deteriorated to a similar extent and, therefore, the Moreland test did not detect significant changes in the values of the measured parameters. The only change is the Rayleigh test parameter $R_{1}$, which confirmed the improvement in green color vision following surgery. When analyzing the impact of blue light sensitivity on the visual system, the effect of cyanopsia must also be taken into account. It results in increased sensitivity to blue light immediately after cataract surgery [36]. It is a purely subjective state which may be caused by a physical or functional condition of the eye or brain or may be purely psychological. Cyanopsia, if unaccompanied by any other sign or symptom, is not an indication of any disease or disorder. The time scale of the effect measured using the achromatic-point settings comprises mainly the first 5-8 hours following the surgery [36]. Thus, it is recommended to perform color vision measurements at least 24 hours following cataract surgery in order to avoid false results related to cyanopsia. It was one of the reasons why the anomaloscopic parameters were measured 2 to 4 weeks following the surgery.

The current study compared the IOL eye with the cataract eye, however, the extent of color vision deterioration in cataract eye due to the natural aging of visual system remains unclear. This study did not compare anomaloscopic parameters with age-matched non-cataract subjects but with eyes following IOL implantation. As described by Mehta [24], color vision deterioration in elderly cataract patients depends, to a certain extent, on natural aging of the lens. Therefore, the effect of cataract itself might be less significant than described in this paper. The issue requires further future analysis. Another concern is related to the differences in the absorption spectra between IOLs and human lenses. Such spectra of human lenses of different age and three exemplary IOLs were presented by Artigas et al. [35]. They showed that the transmittance of the analyzed transparent IOL was significantly higher in the range of approximately $400-530 \mathrm{~nm}$ as compared to crystalline lenses of 40-80 years old subjects. This observation may partially explain the improvement in green and blue color vision following surgery and the slight differences between the SEs and the normal ranges based on the examination of 178 eyes, which was discussed in our previous study [26]. The initial results obtained using an anomaloscope in order to determine color vision disorders in cataract patients are in general consistent with the previous quantitative studies performed by Ao et al. and Mehta et al. [23, 24]. The deterioration of color vision affected mainly the blue and green range. However, the severity of deterioration affecting the two colors may differ between individuals. Thus, certain subjects exhibited mainly a deterioration in the range of blue color and, to a lesser extent, in the range of green. The subjects exhibited a decrease in $M_{1}$ to the lower limit of the scale $\left(M_{1}=1\right)$ in the cataract eye. Other subjects exhibited similar deterioration in both color ranges (blue and green), which resulted in a relative difference between blue and green. It was not visible in the Moreland test but only in the $\mathrm{R}_{1}$ parameter of the Rayleigh test which was shifted towards green (worse green visibility). Finally, certain individuals might show a more severe deterioration in green color visibility as compared to blue, which caused an increase in $M_{2}$ up to the upper limit of the scale $\left(M_{2}=99\right)$ and a larger decrease in $R_{1}$. Such differences depend most probably on the type of cataract. Nevertheless, interpersonal differences in blue-green color vision might significantly influence the results. Thus, the conclusions discussed above must be treated with caution. In all the analyzed subgroups, a decrease in the $\mathrm{R}_{1}$ parameter of the Rayleigh test was observed in cataract eyes, which indicates a general deterioration in green color visibility in the cataract eyes. The increase in $R_{1}$ following surgery was observed in 11 subjects but a decrease, from 43 to 42 , was noted only in one case.

\section{Limitations of the study}

A relatively small number of subjects participating in the study suggests that the results should be treated with caution. The results indicate different types of color vision deterioration depending on the characteristics of cataract. However, it is difficult to estimate the actual proportion of these types in a larger cataract patient population. In order to clarify that, it is required to repeat the measurements in a larger group of cataract patients.

In this study, due to the age of the participants and highly advanced cataracts in the SEs, color vision was compared between both eyes rather than in the same eye before and after the surgery. It seems interesting to study the cataract-related changes in the same eye, both prior to and fol- 
lowing cataract surgery, and this aspect will be subject to further research of this team in the future.

\section{CONCLUSIONS}

It may be concluded that the most suitable anomaloscopic parameters, which seem useful for detecting cataract-induced changes in crystalline lens transparency, are: $R_{1}, M_{1}$ and $M_{2} \cdot M_{2}$ seems to be the most specific and valuable parameter as it increased to the upper limit of the scale $\left(\mathrm{M}_{2}=\right.$ 99) in 6 out of 12 subjects, especially that such increase was not observed in our previous study including 178 eyes. The decrease in $M_{1}$ to the lower limit of the scale $\left(M_{1}=1\right)$ might be characteristic of cataract, however, similar results were also obtained in certain healthy subjects [26]. The results presented in this initial study must be treated with some caution due to the relatively small number of participants. The presented mean values and statistical significance may differ when larger cataract and surgery patient populations are analyzed. Primarily, the results which are close to $p=0.05$ may change in larger populations. Similarly, it is difficult to predict the exact percentages of different color vision deterioration types (dominant blue / dominant green / similar for blue and green) in a large population. This aspect will also become the subject of the authors' further research. Nevertheless, the presented statistics showed a high level of significance (reaching $\mathrm{p}<0.001$ ) in a number of comparisons, which indicates a relatively strong impact of cataract and surgery on color vision.

\section{CORRESPONDENCE}

Krzysztof Piotr Michalak, MD, PhD ORCID

Laboratory of Vision Science and Optometry,

Jacek Zabel - ID - http://orcid.org/0000-0002-6657-8687

Faculty of Physics, Adam Mickiewicz University in Poznan

61-614 Poznań, ul. Uniwersytetu Poznańskiego 2

Krzysztof P. Michalak - ID - http://orcid.org/0000-0002-0267-5605

Jan Olszewski - ID - http://orcid.org/0000-0002-6032-3077

e-mail:kmichalak@amu.edu.pl

Anna Przekoracka-Krawczyk - ID - http://orcid.org/0000-0003-2401-4135

\section{References}

1. Sabesan R, Schmidt BP, Tuten WS et al. The elementary representation of spatial and color vision in the human retina. Sci Adv. 2016; 2(9): e1600797.

2. Danilova MV, Mollon JD. Foveal color perception: minimal thresholds at a boundary between perceptual categories. Vision Res. 2012; 62: 162-72.

3. Conway BR. Color vision, cones, and color-coding in the cortex. Neuroscientist. 2009; 15(3): 274-90.

4. Xiao Y. Processing of the S-cone signals in the early visual cortex of primates. Vis Neurosci. 2014; 31(2): 189-95.

5. Smithson HE. S-cone psychophysics. Vis Neurosci. 2014; 31(2): 211-25.

6. Paramei GV, Oakley B. Variation of color discrimination across the life span. J Opt Soc Am A Opt Image Sci Vis. 2014; 31(4): A375-84.

7. Werner A, Bayer A, Schwarz G et al. Effects of ageing on postreceptoral short-wavelength gain control: transient tritanopia increases with age. Vision Res. 2010; 50(17): 1641-8.

8. Suzuki TA, Qiang Y, Sakuragawa S et al. Age-related changes of reaction time and p300 for low-contrast color stimuli: Effects of yellowing of the aging human lens. J Physiol Anthropol. 2006; 25(2): 179-87.

9. Shinomori K, Werner JS. Impulse response of an S-cone pathway in the aging visual system. J Opt Soc Am A Opt Image Sci Vis. 2006; 23(7): 1570-7.

10. Wuerger S. Colour constancy across the life span: evidence for compensatory mechanisms. PLoS One. 2013; 8(5): e63921.

11. Beirne RO, Mcllreavy L, Zlatkova MB. The effect of age-related lens yellowing on Farnsworth-Munsell 100 hue error score. Ophthalmic Physiol Opt. 2008; 28(5): 448-56.

12. Foster DH. Color constancy. Vision Res. 2011; 51(7): 674-700.

13. Werner A. Spatial and temporal aspects of chromatic adaptation and their functional significance for colour constancy. Vision Res. 2014; 104: 80-9.

14. Webster MA, Juricevic I, McDermott KC. Simulations of adaptation and color appearance in observers with varying spectral sensitivity. Ophthalmic Physiol Opt. 2010; 30(5): 602-10.

15. Miyata K, Yokishawa T, Mine M et al. Cataract Surgery and Visual Acuity in Elderly Japanese: Results of Fujiwara-kyo Eye Study. Biores Open Access. 2017; 6(1): 28-34.

16. Zuo L, Zou H, Xu W et al. The impact of unilateral or bilateral cataract surgery on visual acuity and life quality of elderly patients. J Ophthalmol. 2015; 2015: 509049. 
17. Langina-Jansone Z, Truksa R, Ozolinsh M. Visual acuity and color discrimination in patients with cataracts. J Opt Soc Am A Opt Image Sci Vis. 2020; 37(4): A212-A216.

18. Tengroth BM. Visual experience of the cataract patient after surgery. J Cataract Refract Surg. 2014; 40(7): 1250-1.

19. Kara-Junior N, Espindola RF, Gomes B et al. Effects of blue light-filtering intraocular lenses on the macula, contrast sensitivity, and color vision after a long-term follow-up. J Cataract Refract Surg. 2011;37(12): 2115-9.

20. Ventruba J. [The influence of IOL implantation on visual acuity, contrast sensitivity and colour vision 2 and 4 months after cataract surgery]. Cesk Slov Oftalmol. 2006; 62(2): 133-43.

21. Rodriguez-Galietero A, Montes-Mico R, Munoz G et al. Comparison of contrast sensitivity and color discrimination after clear and yellow intraocular lens implantation. J Cataract Refract Surg. 2005; 31(9): 1736-40.

22. Fristrom B, Lundh BL. Colour contrast sensitivity with different intraocular lens materials in the right and left eyes in same day surgery. Acta Ophthalmol Scand. 2005; 83(4): 443-7.

23. Ao M, Li X, Qiu W et al. The impact of age-related cataracts on colour perception, postoperative recovery and related spectra derived from test of hue perception. BMC Ophthalmol. 2019; 19(1): 56.

24. Mehta U, Diep A, Nyguyen K et al. Quantifying Color Vision Changes Associated With Cataracts Using Cone Contrast Thresholds. Transl Vis Sci Technol. 2020; 9(12): 11.

25. Fanlo Zarazaga A, Gutierrez Vasquez J, Pueyo Royo V. Review of the main colour vision clinical assessment tests. Arch Soc Esp Oftalmol (Engl Ed). 2019; 94(1): 25-32.

26. Zabel J, Przekoracka-Krawczyk A, Olszewski J et al. Variability of Rayleigh and Moreland test results using anomaloscope in young adults without color vision disorders. PLoS One. 2021; 16(5): e0251903.

27. Michalak KP, Zabel J, Wojtyła-Buciora P et al. Application of Blue Filters Increases the Usefulness of Moreland Test in Anomaloscopic Color Vision Assessment for Blue-Green Color Range. Int J Environ Res Public Health. 2021; 18(14): 7654.

28. Nguyen-Tri D, Overbury O, Faubert J. The role of lenticular senescence in age-related color vision changes. Invest Ophthalmol Vis Sci. 2003; 44(8): 3698-704.

29. Schneck ME, Haegerstrom-Portnoy G, Lott LA et al. Comparison of panel D-15 tests in a large older population. Optom Vis Sci. 2014; 91(3): 284-90.

30. Chylack LT Jr., Wolfe JK, Singer DM et al. The Lens Opacities Classification System III. The Longitudinal Study of Cataract Study Group. Arch Ophthalmol. 1993; 111(6): 831-6.

31. OO G. HMS Anomaloskop MR-Instruction Manual. GmbH OO: Berlin, Germany, 2011: 1-31.

32. Wissiak E, Ardjomand N, Steinwender G et al. Influence of light filters in intraocular lenses on color perception and contrast acuity. J Cataract Refract Surg. 2015; 41(6): 1217-23.

33. Wirtitsch MG, Schmidinger G, Prskavec M et al. Influence of blue-light-filtering intraocular lenses on color perception and contrast acuity. Ophthalmology. 2009; 116(1): 39-45.

34. Mantyjarvi M, Syrjakoski J, Tuppurainen K et al. Colour vision through intraocular lens. Acta Ophthalmol Scand. 1997; 75(2): 166-9.

35. Artigas JM, Felipe A, Navea A et al. Spectral transmission of the human crystalline lens in adult and elderly persons: color and total transmission of visible light. Invest Ophthalmol Vis Sci. 2012; 53(7): 4076-84.

36. Kitakawa T, Nakadomari S, Kuriki I et al. Evaluation of early state of cyanopsia with subjective color settings immediately after cataract removal surgery. J Opt Soc Am A Opt Image Sci Vis. 2009; 26(6): 1375-81.

Authors' contributions:

Jacek Zabel: data curation, formal analysis, funding acquisition, software, validation, writing - original draft;

Krzysztof P. Michalak: conceptualization, formal analysis, methodology, supervision, writing - original draft;

Jan Olszewski: conceptualization, methodology, supervision; Anna Przekoracka-Krawczyk: conceptualization,

validation, writing - original draft; Maciej Koszałkowski: funding acquisition, validation.

Conflict of interest:

None.

Financial support:

None.

Ethics:

The content presented in the article complies with the principles of the Helsinki

Declaration, EU directives and harmonized requirements for biomedical journals. 